\title{
Analisis TPM Mesin Pemotong Tekstil Otomatis CNC-Cutter Kuris Dengan Metode OEE di PT. Yifan Jaya
}

\author{
Iwan Nugraha Gusniar ${ }^{1}$, Alfian Sidik ${ }^{2}$ \\ Fakultas Teknik, Universitas Singaperbangsa Karawang ${ }^{1,2}$ \\ Email: iwan.nugraha@ft.unsika.ac.id ${ }^{1}, 1810631150043 @$ student.unsika.ac.id $^{2}$ \\ DOI: http://dx.doi.org/10.31869/rtj.v5i1.2733
}

\begin{abstract}
The CNC-Cutter C 3030 machine is one of the most reliable automatic textile cutting machines in increasing production time efficiency. This machine functions as an automatic cloth or textile cutting machine using a program so that the designs that have been formed can be directly input to the machine and the machine will cut the fabric according to the design. The purpose of this study is to determine the value of the effectiveness of production on the CNC-Cutter C 3030 machine, the value of effectiveness includes availability, performance rate and quality rate, the research method is carried out with the total productive maintenance method, after doing the research, the availability value is $86.26 \%$ at every week, the value of the performance rate is $96.8 \%$, the machine quality rate shows a result of $96.8 \%$, and the calculation result of Overall Equipment Effectiveness is $80.83 \%$
\end{abstract}

Keywords: CNC Cutter Machine, total productive maintenance, maintenance.

\section{PENDAHULUAN}

Pada dunia industri khususnya perusahaan tekstil/garmen untuk saat ini permintaan pasar semakin meningkat yang menekan produksi yang lebih banyak lagi, sehingga diperlukan mesin-mesin otomatis yang dapat bekerja dengan cepat dan rapih. Untuk sekarang ini sudah banyak proses produksi garmen yang melibatkan mesin mulai dari pemotongan pola secara otomatis hingga pemotongan kain yang presisi dan rapih.

Salah satu mesin yang berpengaruh adalah mesin CNC-Cutter C 3030 Kuris atau pemotong kain otomatis di PT. YIFAN JAYA. CNC-Cutter C 3030 Kuris merupakan mesin pemotong kain otomatis dengan menggunakan program desain yang diinput melalui komputer. Setiap alat/mesin memerlukan pemeliharaan ataupun perbaikan secara berkala agar mesin dapat berkerja secara maksimal sehingga proses produksi tetap berjalan.

Adapun rumusan masalah pada penelitian ini yaitu:

1. Bagaimana perawatan pada mesin $\mathrm{CNC}$ Cutter C3030?

2. Bagaimana metode TPM (total productive maintenance) pada perawatan mesin CNC-Cutter C3030?

Adapun tujuan penelitian ini sebagai berikut:

1. Untuk mengetahui perawatan pada mesin CNC-Cutter C3030.
2. Untuk mengetahui metode TPM (total productive maintenance) pada perawatan mesin CNC-Cutter C3030.

\section{TPM (total productive maintenance)}

merupakan sebuah cara yang bertujuan untuk memaksimalkan efektivitas dari suatu mesin atau fasilitas yang digunakan dalam bisnis. TPM juga mencakup berbagai aspek operasi dan instalasi fasilitas tersebut dan dapat menjadi pengarah orang-orang yang bekerja di dalam perusahaan. TPM adalah suatu cara inovatif terhadap maintenance yang mengoptimalkan kinerja mesin, mengeliminasi breakdown, dan perawatan mandiri yang dilakukan oleh operator mesin. Tujuannya adalah untuk meningkatkan produksi serta meningkatkan moral tenaga kerja dan kepuasan kerjanya. (Nakajima, 1988 ).

metode TPM saat melakukan perhitungan tidak dapat berdiri sendiri atau perlu adanya pendukung untuk menyeimbangi standard yang digunakan disetiap diperusahaan manapun, maka dari itu kali ini akan dilakukan perhitungan dengan menggunakan Overall Equipment Effeciveness yang sudah ditetapkan sebagai stand dunia.

OEE (overall equipment effectiveness) adalah suatu metode untuk mengetahui besarnya efektivitas yang dimiliki oleh peralatan atau mesin dengan menghitung nilai availability, performance rate dan quality rate. 
Berikut adalah standar dunia dari masingmasing variable.

Tabel 1 nilai standar dunia overall equipment effectiveness

\begin{tabular}{|c|c|}
\hline Factor OEE & Standar Dunia \\
\hline Availability & $90 \%$ \\
\hline Performance & $95 \%$ \\
\hline Quality & $99,9 \%$ \\
\hline OEE & $85 \%$ \\
\hline
\end{tabular}

\section{Availability}

Untuk menentukan nilai Availability digunakan persamaan sebagai berikut:

$$
\mathrm{AV}=
$$

Running time - planned downtime-Hari

Running time-planneed downtime

$\times 100 \%$

Dimana:

Running Time $=$ waktu pengoperasian (jam)

Planned downtime $=$ waktu henti yang direncanakan (jam)

Hari $=$ hari kerja

\section{performance rate}

Data yang dibutuhkan untuk menghitung performance rate adalah data operation time perminggu, dari data aktual produksi perminggu, dan waktu siklus ideal produk. perhitungan performance rate yang digunakan adalah data sebagai berikut:

$$
P F=\frac{\text { jumlah produksi } x \text { waktu sik }}{\text { waktu operasi ef ekti }}
$$

quality rate

Data yang digunakan untuk menghitung quality rate adalah data jumlah total produksi dalam satu bulan dan data reject. Data produk yang lolos pengujian kualitas tanpa dilakukan repair terlebih dahulu dan langsung bisa masuk ke dalam proses selanjutnya.

$$
\begin{aligned}
\text { quality rate } & =\frac{\text { total produksi }-t}{\text { total } p} \\
X 100 \% &
\end{aligned}
$$

\section{Overall equipment effectiveness}

Hubungan dari ketiga komponen tersebut merupakan nilai efektivitas produksi pada mesin boiler dapat dilihat pada rumus berikut ini:

$O E E=$ Availability $(\%) \mathrm{xPerforma}$ $\mathrm{x}$ Quality rate $(\%)$

\section{METODE PENELITIAN}

Metode Pengambilan data yang dilakukan di PT. YIFAN JAYA yang bertempat di Jl. Ruko Cempaka Mas, RW.8, Sumur Batu, Kec. Kemayoran, Kota Jakarta Pusat, Daerah Khusus Ibukota Jakarta 10640. dengan menggunakan 3 metode yaitu:

1. Observasi

Merupakan metode pengambilan data yang dilakukan dengan cara pengamatan di lapangan secara langsung.

2. Wawancara

Merupakan metode pengambilan data dengan menanyakan secara langsung kepada pihak terkait.

3. Studi literatur

Merupakan metode pengambilan data dengan mencari referensi berisi kajian dan teori terkait permasalahan yang ada.

\section{HASIL DAN PEMBAHASAN}

Pengambilan data yang dilakukan di PT. YIFAN JAYA berdasarkan data produksi bulan mei 2021.

\section{Availability}

untuk menghitung availability diperlukan running time yaitu waktu produksi tanpa mempertimbangkan downtime yang terjadi, di PT. YIFAN JAYA ini mesin beroperasi seninjumat mesin beroperasi selama 8 jam perharinya sedangkan sabtu hanya 5 jam, Setelah didapatkan nilai running time setiap minggu, kemudian dapat dilakukan perhitungan availability. Sebagai contoh, perhitungan availability yang digunakan adalah data pada minggu ke-1 dengan memasukan nilainya sebagai berikut: 
$\mathrm{AV}=$

Running time - planed downtime - Hari

Running time-planned downtime $\times 100$ $\%$

$$
A V=\frac{45-1,5-6}{45-1,5} X 100 \%
$$

$A V=86,20 \%$

Tabel 2 hasil perhitungan availability

\begin{tabular}{|c|l|l|r|l|l|}
\hline No. & $\begin{array}{l}\text { Ming } \\
\text { gu }\end{array}$ & H & $\begin{array}{c}\text { RT } \\
\text { (jam) }\end{array}$ & $\begin{array}{l}\text { P } \\
\text { D }\end{array}$ & $A V(\%)$ \\
\hline 1 & $\begin{array}{l}\text { Ming } \\
\text { gu ke- } \\
1\end{array}$ & 6 & 45 & 1,5 & $86,20 \%$ \\
\hline 2 & $\begin{array}{l}\text { Ming } \\
\text { gu ke- } \\
2\end{array}$ & 6 & 45 & 1,5 & $86,30 \%$ \\
\hline 3 & $\begin{array}{l}\text { Ming } \\
\text { gu ke- } \\
3\end{array}$ & 6 & 45 & 1,5 & $86,27 \%$ \\
\hline 4 & $\begin{array}{l}\text { Ming } \\
\text { gu ke- } \\
4\end{array}$ & 6 & 45 & 1,5 & $86,30 \%$ \\
\hline \multicolumn{3}{|c|}{ Rata - rata } \\
\hline
\end{tabular}

Keterangan:

RT $($ Running Time $)=$ waktu pengoperasian (jam)

$\mathrm{PD}$ (Planned downtime) $=$ waktu henti yang direncanakan (jam)

$\mathrm{H}$ (Hari) = hari kerja

$\mathrm{AV}=$ availability $(\%)$

Dari hasil tabel perhitungan diatas dapat disimpulkan bahwa kondisi atau ketersediaan dari mesin CNC-Cutter C3030 termasuk baik, karena nilai availability berada di atas standar OEE yaitu 86,26\% seperti terlihat pada tabel 1 standar dunia OEE yaitu minimal $85 \%$. Naik turunnya nilai availability mesin CNC-Cutter C3030 ini disebabkan oleh jumlah waktu produksi yang tersedia, faktor lainnya yang mempengaruhi nilai availability terdapat adanya keterhambatan jalannya proses produksi baik dari segi manusia ataupun mesin.

\section{performance rate}

Data yang dibutuhkan untuk menghitung performance rate adalah data operation time (waktu operasi efektif) sama dengan running time perminggu, data aktual produksi perminggu, dan waktu siklus ideal produk. Sebagai contoh, perhitungan performance rate yang digunakan adalah data pada minggu ke- 1 dengan memasukan nilainya sebagai berikut:

$$
P F=\frac{\text { jumlah produksi } x \text { waktu siklus ideal }}{\text { waktu operasi ef ektif }} \times 100 \%
$$$$
P F=\frac{2550 \times 0,0166}{45} X 100 \%
$$

$P F=94,06 \%$

Tabel 3 hasil perhitungan performance rate

\begin{tabular}{|l|l|l|l|l|l|}
\hline no. & $\begin{array}{c}\text { Mingg } \\
\mathrm{u}\end{array}$ & $\begin{array}{c}\text { Juml } \\
\text { ah } \\
\text { PA }\end{array}$ & $\begin{array}{l}\text { Waktu } \\
\text { siklus } \\
\text { (jam) }\end{array}$ & $\begin{array}{c}\text { OP } \\
\text { (jam) }\end{array}$ & $\begin{array}{c}P F \\
\%\end{array}$ \\
\hline 1. & $\begin{array}{l}\text { Mingg } \\
\text { u ke-1 }\end{array}$ & 2550 & 0,0166 & 45 & 94,0 \\
\hline 2. & $\begin{array}{l}\text { Mingg } \\
\text { u ke-2 }\end{array}$ & 2700 & 0,0166 & 45 & $\begin{array}{l}99,6 \\
\%\end{array}$ \\
\hline 3. & $\begin{array}{l}\text { Mingg } \\
\text { u ke-3 }\end{array}$ & 2650 & 0,0166 & 45 & 97,7 \\
\hline 4. & $\begin{array}{l}\text { Mingg } \\
\text { u ke-4 }\end{array}$ & 2600 & 0,0166 & 45 & 95,9 \\
\hline \multicolumn{5}{|c|}{ Rata-rata } & 96,8 \\
\hline
\end{tabular}

Keterangan:

PA $($ produksi aktual $)=$ jumlah produk yang diproduksi selama 1 minggu.

$\mathrm{OP}$ (operation time) = waktu operasi efektif sama dengan running time perminggu (jam)

$$
\mathrm{PF}=\text { performance rate }(\%)
$$

Hasil perhitungan performance rate adalah 96,8\% Dengan kata lain, waktu efektif mesin beroperasi hanya digunakan senilai 96,8\% untuk berproduksi. Nilai ini sudah ideal, karena standar OEE untuk performace rate adalah $95 \%$ seperti dapat dilihat standar dunia OEE. Meski telah idealnya nilai performance rate yang telah dihitung di atas, masih belum dapat dipastikan bahwasannya pada mesin CNC-Cutter C 3030 Kuris ini telah memenuhi standar yang ditetapkan.

\section{quality rate}

Data yang digunakan untuk menghitung quality rate adalah data jumlah total produksi dalam satu minggu dan data reject Sebagai contoh, perhitungan quality rate yang digunakan adalah data pada minggu ke-1 dengan memasukan nilainya sebagai berikut:

quality rate $=\frac{\text { total produksi }- \text { total barang cacat }}{\text { total produksi }}$ 


$$
\text { quality rate }=\frac{2550-76}{2550} \times 100 \%
$$

quality rate $=97,0 \%$

Tabel 4 hasil perhitungan quality rate

\begin{tabular}{|c|c|c|c|c|}
\hline no. & $\begin{array}{c}\text { Mingg } \\
\mathrm{u}\end{array}$ & $\begin{array}{c}\text { Jumlah } \\
\text { Produksi Ideal } \\
\end{array}$ & $\begin{array}{l}R e j \\
e c t\end{array}$ & quality \\
\hline 1. & $\begin{array}{l}\text { Mingg } \\
\text { u ke-1 }\end{array}$ & 2550 & 76 & $97,0 \%$ \\
\hline 2. & $\begin{array}{l}\text { Mingg } \\
\text { u ke-2 }\end{array}$ & 2700 & 96 & $96,4 \%$ \\
\hline 3. & $\begin{array}{l}\text { Mingg } \\
\text { u ke-3 }\end{array}$ & 2650 & 82 & $96,9 \%$ \\
\hline 4. & $\begin{array}{l}\text { Mingg } \\
\text { u ke-4 }\end{array}$ & 2600 & 78 & $97 \%$ \\
\hline \multicolumn{4}{|c|}{ Rata - rata } & $96,8 \%$ \\
\hline
\end{tabular}

Hasil perhitungan quality rate untuk mesin CNC-Cutter C 3030 Kuris adalah senilai 96,8\% dan nilai tersebut belum memenuhi standar dunia yaitu 99,9\%. Reject yang dihasilkan mesin CNC-Cutter C3030 adalah sebanyak rata-rata 83 pcs. Hal ini disebabkan karena sistem mesin belum bekerja secara sempurna, karena speed yang digunakan pada level sedang akibat mesin yang digunakan sudah terlalu tua jika dipaksakan menggunakan kecepatan tinggi akan merusak kain. Kurang baiknya mesin tersebut mengakibatkan nilai dari quality defect and rework meningkat dan quality rate menjadi menurun.

\section{Overall Equipment Effectiveness}

Setelah diperoleh nilai availability pada Tabel 2, performance rate pada Tabel 3 dan quality rate pada Tabel 4 dalam setiap minggu, kemudian dilakukan perhitungan overall equipment effectiveness, Sebagai contoh, perhitungan Overall Equipment Effectiveness yang digunakan adalah data pada minggu ke-1 dengan memasukan nilainya sebagai berikut:

\section{$O E E=$ Availability rate(\%) $\mathrm{x}$ Performance rate(\%) $\mathrm{x}$ Quality rate(\%) \\ $O E E=86,20 \times 94,0 \times 97,0$ \\ $O E E=78,59 \%$}

Tabel 5 hasil perhitungan Overall Equipment Effectiveness

\begin{tabular}{|c|l|c|c|c|c|}
\hline no. & Minggu & $\begin{array}{c}\text { Av } \\
(\%)\end{array}$ & $\begin{array}{c}\text { PF } \\
(\%)\end{array}$ & $\begin{array}{c}\text { QR } \\
(\%)\end{array}$ & $\begin{array}{c}\text { OEE } \\
(\%)\end{array}$ \\
\hline
\end{tabular}

\begin{tabular}{|c|c|c|c|c|c|}
\hline 1. & $\begin{array}{c}\text { Minggu } \\
\text { ke-1 }\end{array}$ & $\begin{array}{l}86, \\
20 \\
\%\end{array}$ & $\begin{array}{l}94, \\
0 \%\end{array}$ & $\begin{array}{l}97, \\
0 \%\end{array}$ & $\begin{array}{c}78,59 \\
\%\end{array}$ \\
\hline 2. & $\begin{array}{c}\text { Minggu } \\
\text { ke-2 }\end{array}$ & $\begin{array}{l}86, \\
30 \\
\%\end{array}$ & $\begin{array}{l}99, \\
6 \%\end{array}$ & $\begin{array}{l}96, \\
4 \%\end{array}$ & $\begin{array}{c}82,86 \\
\%\end{array}$ \\
\hline 3. & $\begin{array}{l}\text { Minggu } \\
\text { ke-3 }\end{array}$ & $\begin{array}{l}86, \\
27 \\
\%\end{array}$ & $\begin{array}{l}97, \\
7 \%\end{array}$ & $\begin{array}{l}96, \\
9 \%\end{array}$ & $81,6 \%$ \\
\hline 4. & $\begin{array}{c}\text { Minggu } \\
\text { ke-4 }\end{array}$ & $\begin{array}{c}86, \\
30 \\
\%\end{array}$ & $\begin{array}{l}95, \\
9 \%\end{array}$ & $\begin{array}{l}97 \\
\%\end{array}$ & $\begin{array}{c}80,27 \\
\%\end{array}$ \\
\hline
\end{tabular}

Keterangan:

$\mathrm{AV}=$ Availability $(\%)$

$\mathrm{PF}=$ Performance rate $(\%)$

$\mathrm{QR}=$ Quality rate $(\%)$

$\mathrm{OEE}=$ Overall Equipment Effectiveness (\%)

Hasil perhitungan Overall Equipment Effectiveness untuk mesin CNC-Cutter C 3030 Kuris adalah $80,83 \%$ dan tidak masuk pada standar OEE seperti dapat dilihat Tabel Standar Dunia OEE. Naik turunnya nilai availability disebabkan adanya set up mesin yang terlambat dengan waktu idealnya. Rendahnya nilai quality rate mesin yaitu kondisi mesin kurang perawatan rutin sehingga membuat mata potong mesin rusak, piston kurang pelumasan, terlambatnya pengecekan knife dan grinding yang mengakibatkan adanya downtime tidak terencana akibat kerusakan mesin yang sudah lama.

\section{PENUTUP}

Berdasarkan penelitian yang telah dilakukan, maka dapatkan kesimpulan sebagai berikut:

1. Mesin CNC-Cutter C 3030 Kuris merupakan mesin pemotong bahan kain otomatis yang sangat canggih dan presisi. Mesin ini memiliki laser knife sebesar $0,1 \mathrm{~mm}$ sebagai penentu titik awal pemotongan, kemudian ada smart knife untuk membuat potongan semakin presisi. dilengkapi dengan 4 sumbu potong yaitu: $\mathrm{X}, \mathrm{Y}, \mathrm{Z}$, dan $\mathrm{C}$ dimana $\mathrm{X}$, $\mathrm{Y}, \mathrm{Z}$ merupakan arah potong pisau sedangkan $\mathrm{C}$ merupakan gerak translasi pisau. Maka dari itu dalam perawatannya cukup kompleks mulai dari perawatan software, kelistrikan, hingga mekanikal 
2. Cara menangani mesin $\mathrm{CNC}$-Cutter $\mathrm{C}$ 3030 Kuris yang sering mengalami trouble yaitu dengan memperbaiki sistem perawatan mesin adanya penggunaan melebihi batas kemampuan dan kurangnnya sistem perawatan secara berkala. Hanya akan dilakukan perawatan apabila ada permasalahan saja, maka diterapkanlah sistem perawatan dengan menggunakan 2 (dua) jenis perawatan yaitu preventive maintenance dan corrective maintenance.

3. Efiktifitas proses produksi dan kapasitas produksi kerja mesin $\mathrm{CNC}$-Cutter $\mathrm{C}$ 3030 Kuris dapat dilihat dari hasil perhitungan yang telah dilakukan ratarata nilai availability $86,26 \%$, performance rate $96,8 \%$, dan quality rate $96,8 \%$. dari hasil tersebut dapat diketahui bahwa kinerja bagian perawatan sudah baik karena waktu breakdown mesin tidak terlalu besar bisa dilihat dari nilai availability yaitu 86,26\% namun sudah memenuhi standar akan tetapi bagian perawatan harus melihat dari quality rate mesin yang masih dibawah nilai standar dunia dan dilihat dari nilai quality rate yaitu $87,24 \%$ dan pada variabel performance rate $99,3 \%$ sudah memenuhi standar yang ada dari standar yang ada.

Quality rate tidak mencapai standar dunia OEE disebabkan oleh adanya reject produk, dipengaruhi oleh sistem mesin belum bekerja secara sempurna atau tidak maksimal dan masih adanya kurang kesadaran operator akan hal SOP pabrik.

Dari Tabel OEE dengan jelas menunjukan setiap minggu adanya naik turun suatu nilai dari availability yang naik turun dengan stabil, performance rate berada dalam nilai stabil dalam kurun waktu 4 minggu dan mengalami kenaikan setalahnya, quality rate mengalami penurunan, yang dimana hal tersebut sangat mempengaruhi kualitas produk produksi yang ideal.

Rata-rata hasil perhitungan Overall Equipment Effectiveness adalah 80,83\%. Nilai ini belum memenuhi standar dunia yaitu $85 \%$.

\section{DAFTAR PUSTAKA}

[1] Rommy, F, P., Hendrik, H., Erry, R. (2020). Total Productive Maintenance pada Perawatan Mesin Grinding Menggunakan Metode Overall Equipment Effectiveness (OEE).

[2] Joel, B, P, A., Evin, D, M., Alfian, H, S. (2017). Penerapan Total Productive Maintenance dengan menggunakan metode OEE pada turbin uap Type C5 DS II-GVS.

[3] Mohamad Nafis, w. w. (n.d.). analisis perhitungan nilai overall equipment effectiveness (OEE) pada mesin wrapping di perusahaan biskuit dan wafer PT. UNIMOS. 1-15.

[4] Achmad Said, J. S. (2008). Analisis Total Productive Maintenance Pada Lini Produksi Mesin Perkakas Guna Memperbaiki Kinerja Perusahaan. IST AKPRIND Yogyakarta.

[5] Springer. (2003). Handbook of reliability engineering. New Jersey USA : Sunrise Setting Ltd, Torquay, Devon, UK

[6] Nakajima, S. (1988). Introduction to Total Productive Maintenance. Productivity Press Inc, Portland.

[7] Ljunberg, O. (1998). Measurement of overall equipment effectiveness as a basis for TPM activities. 